\title{
Ethnic variance in iron status: is it related to dietary intake?
}

Clare R Wall ${ }^{1, *}$, Deborah R Brunt ${ }^{2}$ and Cameron C Grant ${ }^{2,3}$

'Discipline of Nutrition, Faculty of Medicine and Health Sciences, University of Auckland, Private Bag 92019, Wellesley Street, Auckland, New Zealand: ${ }^{2}$ Department of Paediatrics, University of Auckland, Auckland, New Zealand: ${ }^{3}$ General Paediatrics, Starship Children's Hospital, Auckland District Health Board, Auckland, New Zealand

Submitted 10 April 2008: Accepted 24 October 2008: First published online 17 December 2008

\begin{abstract}
Objective: In New Zealand (NZ), Fe deficiency (ID) is present in 14\% of children aged $<2$ years. Prevalence varies with ethnicity (NZ European $7 \%$, Pacific $17 \%$, Maori $20 \%$ ). We describe dietary Fe intake, how this varies with ethnicity and whether intake predicts Fe status.

Design: A random sample of children aged 6-23 months. Usual Fe intake and dietary sources were estimated from $2 \mathrm{~d}$ weighed food records. Associations were determined between adequacy of Fe intake, as measured by the Estimated Average Requirement (EAR), and ID.

Subjects: Sampling was stratified by ethnicity. Dietary and blood analysis data were available for 247 children.

Results: The median daily Fe intake was $8.3 \mathrm{mg}$ (age 6-11 months) and 6.3 mg (age 12-23 months). Breast milk and milk formulas (median 58\%; age 6-11 months), and cereals (41\%) and fruit and vegetables (17\%; age 12-23 months), were the predominant dietary sources of Fe. Fe intake was below the EAR for $25 \%$ of the children. Not meeting the EAR increased the risk of ID for children aged 6-11 months (relative risk $=18 \cdot 45,95 \%$ CI 3·24, 100 00 ) and $12-23$ months (relative risk $=4 \cdot 95,95 \%$ CI $1.59,15 \cdot 41$ ). In comparison with NZ European, Pacific children had a greater daily Fe intake $(P=0 \cdot 04)$ and obtained a larger proportion of Fe from meat and meat dishes $(P=0 \cdot 02)$.

Conclusions: A significant proportion of young NZ children have inadequate dietary Fe intake. This inadequate intake increases the risk of ID. Ethnic differences in Fe intake do not explain the increased risk of ID for Pacific children.
\end{abstract}

Keywords Children's diet Ethnic groups Dietary iron New Zealand
Fe deficiency (ID) in children aged $<2$ years is twice as prevalent in New Zealand (NZ) as it is in Australia, Europe or the USA ${ }^{(1-3)}$. ID prevalence varies with ethnicity within NZ, being two to four times more prevalent in ethnic groups of non-NZ European origin ${ }^{(4)}$.

Development of effective national policy is central to the reduction of ID prevalence. In the USA, ID prevalence has decreased over the past 30 years in association with policy which has increased Fe intake ${ }^{(5,6)}$. Currently, less than $1 \%$ of US children in this age group have inadequate Fe intakes ${ }^{(7)}$. In contrast, in the UK, where policy is less well developed, Fe intake is lower with $89 \%$ of children aged 1.5 to 4.5 years having a daily intake below the recommended $6.9 \mathrm{mg}^{(8)}$.

Ethnic variability in ID prevalence is not always due to dietary intake. For example, the higher prevalence in Alaskan natives is partly due to increased gastrointestinal blood loss secondary to Helicobacter pylori infection ${ }^{(9)}$. This infection is also common in Pacific ethnic groups in $\mathrm{NZ}{ }^{(10)}$. The prevalence of ID in Pacific children is 2.5 times greater than in NZ European children ${ }^{(4)}$.
To determine the potential for policy aimed at increasing Fe intake to reduce ID prevalence in NZ, we determined the proportion of children with adequate dietary $\mathrm{Fe}$ intake, whether dietary $\mathrm{Fe}$ intake varied between ethnic groups and whether Fe intake was associated with Fe status in different ethnic groups.

\section{Methods}

\section{Study design}

An ethnically stratified random sample of children aged 6-23 months, resident in Auckland, NZ, was enrolled in order to determine the prevalence of ID $^{(4)}$. Eligible children were identified from random residential address start points with cluster sampling from the twenty consecutive dwellings to the right of each start point. Ethnicity was defined by the child's caregiver. The present paper reports the data from the children who were enrolled in this prevalence study and from whom accurate $2 \mathrm{~d}$ weighed food record data were obtained. 
There were no exclusion criteria. Enrolment of children with an acute infection was deferred for one month. The Health Funding Authority Ethics Committee approved the study.

\section{Data collection}

Data were collected in the child's home. Written informed consent was obtained, the child's caregiver interviewed and topical anaesthetic cream applied (EMLA, 2.5\% lignocaine$2.5 \%$ prilocaine; AstraZeneca Ltd, Auckland, New Zealand).

Weight and length were measured supine. The mean of three serial measurements from each child, wearing light clothing and no shoes, was taken. These data were then converted to Z-scores using the WHO Anthro 2005 software package (WHO, Geneva, Switzerland), which uses data collected in the WHO Multicentre Growth Reference Study ${ }^{(11)}$.

\section{Dietary intake assessment}

The caregivers were instructed on how to measure and accurately record all the food and drink consumed by the child over two non-consecutive days. All food was weighed on a digital electronic scale with a tare function. Provision was made for when meals were consumed outside the home. Telephone contact was maintained to assist with compliance and accuracy of recording.

Nutrient content of the weighed food intake records was determined from the NZ food composition database using the Foodworks Professional software package edition 3.02 (Xyris Software (Australia) Pty Ltd, Brisbane, Australia) ${ }^{(12)}$. Breast milk intake was estimated using published reference data for infants receiving mixed diets ${ }^{(13)}$. These estimations included breast-fed infants supplemented with other milks. The reference data were reported for ages 6, 9 and 12 months ${ }^{(13)}$. For estimating intake volumes in our study we used the 6 month volumes for children from 6 to $<7 \cdot 5$ months old, the 9 month volumes for children from 7.5 to $<10.5$ months old and the 12 month volumes for children from 10.5 to $<13.5$ months old ${ }^{(13)}$. Data from children consuming less food than usual as quantified by their caregivers or for whom incomplete diaries were provided were excluded from analyses.

The main food sources of Fe were identified. For foods not in the database, recipes were made if ingredients were available or a best match made with the food items listed in the database. Meat and meat products were examined separately and then combined to describe haem Fe intake. Fe from other sources was considered non-haem. Total daily Fe intake and Fe intake from the different sources were determined for each day of dietary intake data. Probability estimates of usual dietary nutrient intake were made using the C-Side software (Iowa State University, Ames, IA, USA) ${ }^{(14)}$.

In 2006, NZ adopted new nutrient reference values (Table 1$)^{(15)}$. These included revision of the Recommended Dietary Intakes (RDI), estimated Adequate Intakes (AI) where RDI could not be calculated, and introduced an
Table 1 New Zealand nutrient reference values for dietary iron intake for children aged 6-23 months ${ }^{(15)}$

\begin{tabular}{lcc}
\hline & \multicolumn{2}{c}{ Age group } \\
\cline { 2 - 3 } & $6-11$ months & 12-23 months \\
\hline $\operatorname{RDI}^{*}(\mathrm{mg} / \mathrm{d})$ & 11 & 9 \\
$\operatorname{EARt}(\mathrm{mg} / \mathrm{d})$ & 7 & 4 \\
\hline
\end{tabular}

${ }^{*}$ Recommended Dietary Intake; the daily intake sufficient to meet the nutrient requirements of nearly all (97-98\%) healthy individuals. tEstimated Average Requirement; the daily intake necessary to meet the requirements of half the healthy individuals.

Estimated Average (daily) Requirement (EAR). The RDI was increased and the EAR was established to provide a more practical estimate of dietary requirements given the wide variability in Fe requirements in this age group ${ }^{(15)}$.

\section{Measurement of Fe status}

A venous blood sample was collected. Full blood count, serum transferrin saturation, and serum ferritin and Creactive protein (CRP) concentrations were measured as previously described ${ }^{(4)}$.

ID was defined in a manner similar to the US National Health and Nutrition Examination Surveys (NHANES). In NHANES, ID was present if two or more of ferritin concentration, transferrin saturation and erythrocyte protoporphyrin concentration were abnormal ${ }^{(16)}$. If in addition $\mathrm{Hb}$ concentration was low, then Fe-deficiency anaemia was present. We used the NHANES cut-off values for low Fe saturation $(<10 \%)$, low ferritin concentration $(<10 \mu \mathrm{g} / \mathrm{l})$ and low $\mathrm{Hb}(<110 \mathrm{~g} / \mathrm{l})^{(16)}$. As an appropriate assay for erythrocyte protoporphyrin was not available, mean cell volume was used as the measure of erythrocyte Fe with abnormal defined as $<73 \mathrm{fl}^{(4,17)}$. Children with an elevated CRP (>4 mg/l) were excluded.

\section{Statistical analyses}

Double-entered data were analysed using the Epi-info 2000 (Centers for Disease Control and Prevention, Atlanta, GA, USA) and SAS-PC version 9·1 (SAS Institute, Cary, NC, USA) software packages. Variables that were not normally distributed such as serum ferritin concentration were log-transformed.

Dietary factors associated with Fe status were examined using linear regression analysis, adjusting for the clustered study design and weighted for ethnic stratification using SAS-callable SUDAAN $9 \cdot 0 \cdot 1$ (Research Triangle Institute, Research Triangle Park, NC, USA). Variables examined included food categories of dietary Fe intake and other factors known to influence dietary Fe absorption ${ }^{(18)}$.

\section{Results}

\section{Study sample enrolment}

The $2 \mathrm{~d}$ weighed food record was collected from 247 of 307 children in whom Fe status was measured and CRP 


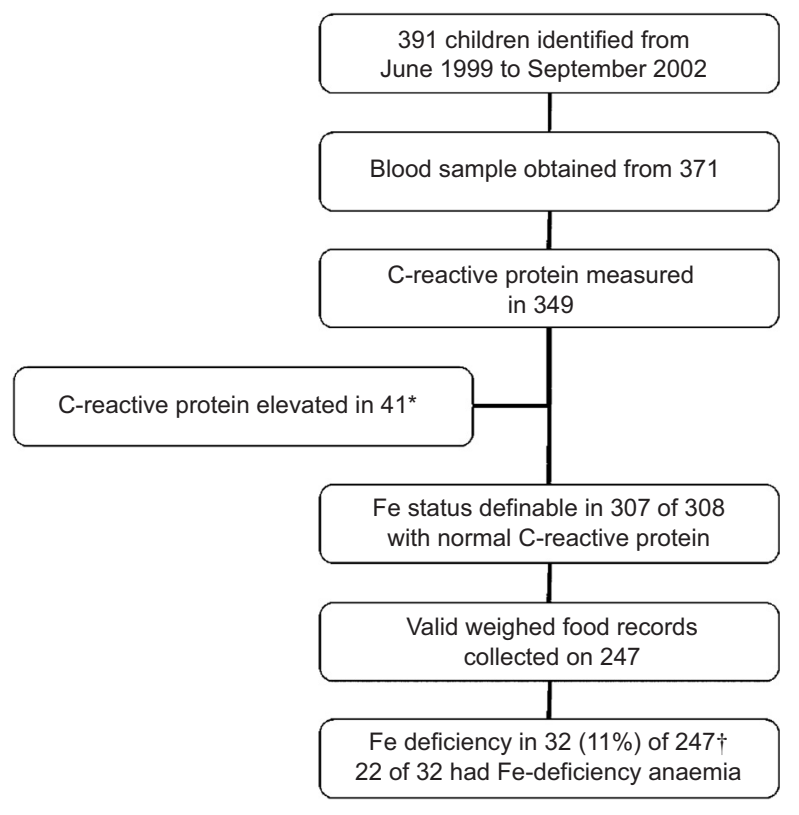

Fig. 1 Summary of enrolment, blood sampling and measurement of dietary iron intake and iron status in the study population: random sample of children aged 6-23 months, resident in Auckland, New Zealand. *New Zealand European, $n$ 12; Maori, $n$ 14; Pacific, $n$ 13; other, $n$ 2. †Percentage adjusted for clustering and weighted for ethnic stratification was normal (Fig. 1). A smaller proportion of those in whom a weighed food recorded was collected were Fe-deficient (11\% v. $27 \%, P=0 \cdot 03)$.

\section{Demographics and antbropometry}

The proportion of the children living in households in the most socially deprived quintile (23\%; Table 2) was comparable to that for the Auckland metropolitan region $(22 \%)^{(20)}$. Seventeen $(6 \%)$ children had a gestation less than 37 weeks and five (2\%) a birth weight less than $2.5 \mathrm{~kg}$. The weight-for-height $Z$-score was greater than zero for 197 (73\%) children. The mean weight-for-height $Z$-score was greater for children aged 12-23 months compared with those aged 6-11 months (1.01 v. 0.55, $P=0 \cdot 01)$. The mothers of $55 \%$ of the children took Fe supplements during pregnancy (Table 2), with this proportion not varying between ethnic groups.

\section{Past and current dietary habits of the children}

Most (93\%) of the children were initially breast-fed, with exclusive breast-feeding continuing for a median of 3 months and any breast-feeding for a median of 7 months (Table 2). Thirty-nine children (25\%) commenced cow's milk prior to age 12 months. Fifty (20\%) did not receive infant or follow-on formula.

Table 2 Demographics, anthropometry and dietary habits of the study population: random sample of children aged 6-23 months, resident in Auckland, New Zealand

\begin{tabular}{|c|c|c|c|c|c|c|}
\hline \multirow[b]{2}{*}{ Variable ( $n 247$ unless stated) } & \multicolumn{6}{|c|}{ Value } \\
\hline & $n$ & $\%$ & Median & 25th, 75th centile & Mean & $95 \% \mathrm{Cl}$ \\
\hline \multicolumn{7}{|l|}{ Child demographics and anthropometry } \\
\hline \multicolumn{7}{|l|}{ Ethnicity } \\
\hline New Zealand European & 102 & 60 & & & & \\
\hline Maori & 60 & 14 & & & & \\
\hline Pacific & 67 & 15 & & & & \\
\hline Other & 18 & 11 & & & & \\
\hline \multicolumn{7}{|l|}{ Socio-economic status } \\
\hline Living in household in most deprived quintile* & 84 & 23 & & & & \\
\hline Female gender & 140 & 56 & & & & \\
\hline Age (months) & & & 14 & 10,19 & & \\
\hline Birth weight $(\mathrm{kg})$ & & & & & $3 \cdot 48$ & $3.41,3.55$ \\
\hline BMI $\left(\mathrm{kg} / \mathrm{m}^{2}\right)(n 243)$ & & & & & $17 \cdot 5$ & $17 \cdot 3,17 \cdot 8$ \\
\hline BMI-for-age Z-score (n 238) & & & & & $0 \cdot 83$ & $0.67,0.99$ \\
\hline Weight-for-height $Z$-score ( $n$ 238) & & & & & $0 \cdot 86$ & $0 \cdot 71,1 \cdot 02$ \\
\hline \multicolumn{7}{|l|}{ Maternal demographics } \\
\hline Age (years) (n 245) & & & 31 & 27,34 & & \\
\hline Took Fe supplements during pregnancy ( $n$ 238) & 127 & 55 & & & & \\
\hline Received tertiary education $(n$ 238) & 131 & 59 & & & & \\
\hline \multicolumn{7}{|l|}{ Milk feeding habits } \\
\hline Breast-fed & 227 & 93 & & & & \\
\hline Months of exclusive breast-feeding ( $n$ 227) & & & 3 & 1,5 & & \\
\hline Months of any breast-feeding ( $n$ 227) & & & 7 & 4,11 & & \\
\hline Age started cow's milk (months) ( $n$ 150) & & & 12 & 11,12 & & \\
\hline Cow's milk only non-human milk consumed ( $n$ 152) & 23 & 15 & & & & \\
\hline Any infant/follow-on formula & 197 & 80 & & & & \\
\hline \multicolumn{7}{|l|}{ Non-milk foods } \\
\hline Age first ate solid food (months) ( $n$ 245) & & & 4 & 3,5 & & \\
\hline Age first ate meat (months) ( $n$ 230) & & & 6 & 5,8 & & \\
\hline Fe supplements $<12$ months of age $(n 246)$ & 7 & 3 & & & & \\
\hline Tea $<12$ months of age $(n 246)$ & 9 & 3 & & & & \\
\hline
\end{tabular}

${ }^{*}$ Household deprivation measured using NZDep2001 Index of Deprivation ${ }^{(19)}$. 
Table 3 Comparison of daily dietary intakes of energy, iron and modifiers of iron absorption for children 6-11 and 12-23 months old, Auckland, New Zealand

\begin{tabular}{|c|c|c|c|c|c|}
\hline & \multicolumn{4}{|c|}{ Age group } & \multirow[b]{3}{*}{$P$ value } \\
\hline & \multicolumn{2}{|c|}{$\begin{array}{l}\text { 6-11 months } \\
(n 77)\end{array}$} & \multicolumn{2}{|c|}{$\begin{array}{l}\text { 12-23 months } \\
(n 170)\end{array}$} & \\
\hline & Median & 25th, 75th centile & Median & 25th, 75th centile & \\
\hline \multicolumn{6}{|l|}{ Daily energy and Fe intakes } \\
\hline Energy intake (kJ/kg body weight) & 325 & 242,389 & 337 & 284,394 & 0.09 \\
\hline Median Fe intake (mg) & $8 \cdot 3$ & $4 \cdot 7,10 \cdot 8$ & $6 \cdot 3$ & $4 \cdot 3,8 \cdot 8$ & 0.04 \\
\hline Fe intake (mg/kg of body weight) & 0.8 & $0.5,1.2$ & 0.5 & $0 \cdot 4,0 \cdot 8$ & $<0.001$ \\
\hline Fe density (mg/MJ) & $2 \cdot 8$ & $2 \cdot 1,3 \cdot 7$ & $1 \cdot 6$ & $1 \cdot 2,2 \cdot 2$ & $<0.001$ \\
\hline \multicolumn{6}{|l|}{$\mathrm{Fe}$ intake from dietary sources (\%) } \\
\hline Meat and meat dishes & 2 & 0,6 & 5 & 1,16 & $<0.001$ \\
\hline Fruit and vegetables & 6 & 2,18 & 17 & 7,28 & 0.09 \\
\hline Cereals & 4 & 0,14 & 41 & 15,60 & $<0.001$ \\
\hline Milk & 0 & 0,0 & 1 & 0,3 & $<0.001$ \\
\hline Breast milk and milk formulas & 58 & 0,86 & 0 & 0,0 & $<0.001$ \\
\hline Fortified infant foods & 1 & 0,17 & 0 & 0,2 & 0.03 \\
\hline \multicolumn{6}{|l|}{ Intake of modifiers of Fe absorption } \\
\hline Vitamin $C(\mathrm{mg} / \mathrm{d})^{*}$ & 90 & 42,125 & 67 & 41,119 & 0.97 \\
\hline $\mathrm{Ca}(\mathrm{mg} / \mathrm{d})^{*}$ & 588 & 261,782 & 560 & 292,771 & 0.97 \\
\hline Fibre $(\mathrm{g} / \mathrm{d})^{\star}$ & 2.9 & $1 \cdot 8,4 \cdot 4$ & $5 \cdot 5$ & $3 \cdot 6,7 \cdot 4$ & $<0.001$ \\
\hline
\end{tabular}

${ }^{*} \log ($ vitamin $\mathrm{C}), \log (\mathrm{Ca})$ and $\log ($ fibre) used in age group comparisons.

Solids were introduced at age 3 months or younger for forty-nine (19\%) children and from 4 to 5 months of age for $144(62 \%)$ children. Solids were introduced at an older age for children of other ethnic groups compared with NZ European children (median $4 \cdot 4 v .3 .6$ months, $P=0 \cdot 03$ ). Meat was introduced at a younger age for Maori compared with NZ European children $(5.7 v$ v. 6.5 months, $P=0 \cdot 001$ ). The $3 \%$ of children who received Fe supplements prior to age 12 months included only one of the seventeen children born prematurely.

\section{Fe and energy intake by age group}

Median energy intake approximated the estimated energy requirements for this age group $(\approx 340 \mathrm{~kJ} / \mathrm{kg}$ body weight $)^{(15)}$. Energy intake per kilogram of body weight did not vary with age $(P=0 \cdot 09$; Table 3$)$ or gender (male v. female: $316 v .351 \mathrm{~kJ} / \mathrm{kg}, P=0 \cdot 38)$.

The median daily dietary Fe intake $(P=0 \cdot 04)$, Fe intake per kilogram of body weight $(P<0 \cdot 001)$ and $\mathrm{Fe}$ intake per megajoule of energy intake $(P<0 \cdot 001)$ were all significantly greater in the 6-11 month compared with the 12-23 month age group (Table 3).

Dietary sources of Fe varied with age (Table 3 ). In comparison with children aged 6-11 months, a larger percentage of the dietary Fe intake for children aged 12-23 months came from meat and meat dishes (5\%v $v$. $2 \%, P<0.001)$, cereals ( $41 \% v .4 \%, P<0.001)$ and milk ( $1 \% v .0 \%, P<0.001)$; and a smaller percentage was from breast milk and milk formulas (0\% v. $58 \%, P<0.001)$ and fortified infant foods (0\%v.1\%,P=0.03).

\section{Intake of modifiers of Fe absorption}

Eighty-four per cent of the children met either the AI (age 6-11 months) or the RDI (age 12-23 months) for vitamin C intake. Sixty-one per cent met the AI (age 6-11 months) or the RDI (age 12-23 months) for daily Ca intake. Although dietary fibre intake was greater in the older age group $(P<0 \cdot 001)$, fibre intake for all children was less than the AI which is defined only for this older age group.

\section{Fe and energy intake by etbnic group}

For children aged 6-11 months, the energy intake, Fe intake and percentage of Fe from different dietary sources did not vary with ethnicity (Table 4). For children aged 12-23 months, the median daily Fe intake for Pacific children was greater than for NZ European children $(7 \cdot 7$ v. $6.3 \mathrm{mg}, P=0.04$; Table 5).

For children aged 12-23 months, the percentage of Fe from different dietary sources varied with ethnicity (Table 5). In comparison with NZ European children, Maori children obtained a larger percentage from cereals ( $52 \% v .37 \%, P=0 \cdot 04)$. In comparison with NZ European children, Pacific children obtained a larger percentage from meat and meat dishes (9\%v. 4\%,P=0.02).

\section{Adequacy of Fe intake and association with Fe deficiency}

For children aged 6-11 months the EAR for Fe was achieved by $59 \%$ and the RDI by $22 \%$, and for children aged $12-23$ months the EAR was achieved by $81 \%$ and the RDI by $22 \%$. In the 12-23 month age group, in comparison with NZ European children, a larger proportion of Pacific children met the RDI ( $40 \% v \cdot 17 \%, P=0 \cdot 01$ ).

Not meeting the EAR was associated with an increased risk of ID for children aged 6-11 months (relative risk $(\mathrm{RR})=18 \cdot 45,95 \% \mathrm{CI} 3 \cdot 24,100 \cdot 00)$ and 12-23 months $(\mathrm{RR}=4.95,95 \%$ CI $1.59,15 \cdot 41)$. For children aged 

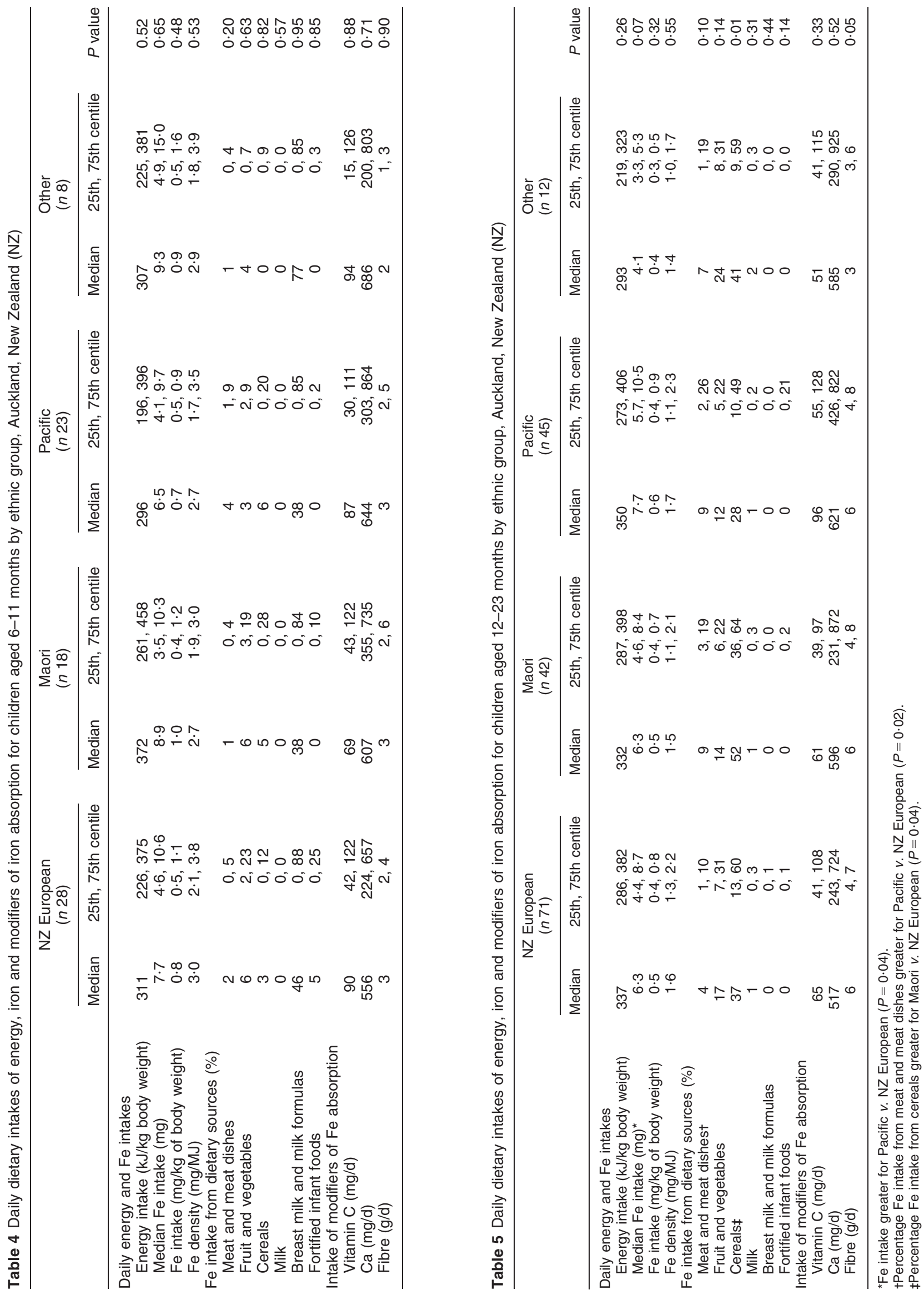
6-11 months, not meeting the RDI was also associated with an increased risk of ID $(\mathrm{RR}=3 \cdot 26,95 \%$ CI $3 \cdot 17$, 100・00).

\section{Fe intake and association with body Fe stores}

Total Fe intake was positively associated with serum ferritin for children aged 6-11 months $(P<0 \cdot 001$; Table 6) and 12-23 months $(P=0 \cdot 01$; Table 7$)$. Within ethnic groups this association of increased $\mathrm{Fe}$ intake with increased serum ferritin was present in the 6-11 month age group for Maori $(P=0 \cdot 03)$, Pacific $(P=0 \cdot 01)$ and children of other non-NZ European groups $(P<0 \cdot 001$; Table 6), and for 12-23-month-old NZ European children $(P=0 \cdot 03$; Table 7$)$.

Table 6 Univariate associations of dietary intake of iron and modifiers of iron absorption with log(serum ferritin; $\mu \mathrm{g} / \mathrm{l})$ for children aged 6-11 months, Auckland, New Zealand (NZ)

\begin{tabular}{|c|c|c|c|c|c|c|c|c|c|c|}
\hline \multirow[b]{3}{*}{ Dietary factor } & \multirow{2}{*}{\multicolumn{2}{|c|}{$\begin{array}{l}\text { All children } \\
\quad(n 77)\end{array}$}} & \multicolumn{8}{|c|}{ Ethnic group } \\
\hline & & & \multicolumn{2}{|c|}{$\begin{array}{l}\text { NZ European } \\
(n \text { 28) }\end{array}$} & \multicolumn{2}{|c|}{$\begin{array}{l}\text { Maori } \\
(n 18)\end{array}$} & \multicolumn{2}{|c|}{$\begin{array}{l}\text { Pacific } \\
(n 23)\end{array}$} & \multicolumn{2}{|c|}{$\begin{array}{l}\text { Other } \\
(n 8)\end{array}$} \\
\hline & $r^{2}(\%)^{*}$ & $P$ value & $r^{2}(\%)$ & $P$ value & $r^{2}(\%)$ & $P$ value & $r^{2}(\%)$ & $P$ value & $r^{2}(\%)$ & $P$ value \\
\hline $\begin{array}{l}\log (\mathrm{Fe} \text { intake; } \mathrm{mg} / \mathrm{d}) \dagger \\
\log (\mathrm{Fe} \text { intake; } \mathrm{mg} / \mathrm{d}) \text { from }\end{array}$ & 22 & $<0.001$ & 7 & $0 \cdot 12$ & 27 & 0.03 & 30 & $0 \cdot 01$ & 64 & $<0 \cdot 001$ \\
\hline Meat and meat dishes & 0 & 0.62 & 8 & 0.07 & 0 & $0 \cdot 88$ & 9 & $0 \cdot 14$ & 9 & $0 \cdot 77$ \\
\hline Fruit and vegetablesł & 5 & $0 \cdot 12$ & 9 & $0 \cdot 16$ & 6 & 0.56 & 13 & $0 \cdot 12$ & 0 & 0.95 \\
\hline Cereals§ & 3 & $0 \cdot 18$ & 9 & 0.03 & 0 & 0.95 & 1 & 0.75 & 0 & 0.97 \\
\hline Milk & 0 & $0 \cdot 66$ & 0 & $0 \cdot 88$ & 4 & 0.47 & 12 & $0 \cdot 12$ & $--^{\star \star}$ & - \\
\hline Breast milk and milk formulas & 11 & 0.02 & 9 & $0 \cdot 15$ & 0 & 0.94 & 31 & 0.003 & 7 & $0 \cdot 77$ \\
\hline Fortified infant foods & 1 & 0.56 & 0 & $0 \cdot 88$ & 1 & 0.65 & 2 & $0 \cdot 61$ & 36 & $0 \cdot 30$ \\
\hline \multicolumn{11}{|c|}{ Other dietary factors and anthropometry } \\
\hline Log(vitamin C intake; mg/d) & 5 & 0.29 & 3 & 0.63 & 13 & 0.03 & 27 & $<0.001$ & 0 & 0.96 \\
\hline Log(Ca intake; mg/d)\| & 11 & 0.01 & 27 & 0.01 & 8 & $0 \cdot 24$ & 6 & $0 \cdot 12$ & 33 & $0 \cdot 50$ \\
\hline Log(dietary fibre intake; g/d) & 3 & 0.32 & 1 & $0 \cdot 70$ & 6 & $0 \cdot 66$ & 11 & 0.25 & 34 & $0 \cdot 48$ \\
\hline Birth weight $(\mathrm{kg}) \Phi$ & 15 & 0.02 & 29 & 0.02 & 9 & $0 \cdot 17$ & 0 & $0 \cdot 94$ & 29 & $0 \cdot 20$ \\
\hline BMI-for-age $Z$-score & 2 & $0 \cdot 17$ & 7 & 0.07 & 16 & $0 \cdot 28$ & 5 & 0.37 & 0 & 0.93 \\
\hline Weight-for-height Z-score & 2 & 0.21 & 6 & $0 \cdot 12$ & 14 & $0 \cdot 31$ & 5 & 0.34 & 1 & 0.82 \\
\hline
\end{tabular}

*Percentage of variance in value of log(serum ferritin) explained by regression model.

tFor all significant associations, as log(Fe intake) increased, log(serum ferritin) increased.

†For Pacific children, as log(Fe from fruit and vegetables) increased, log(serum ferritin) increased.

$\S$ As log(Fe from cereals) increased, log(serum ferritin) decreased.

$\|$ As $\log (\mathrm{Ca})$ increased, log(serum ferritin) decreased.

TAs birth weight increased, log(serum ferritin) increased.

${ }^{\star \star} \beta$ coefficient could not be estimated.

Table 7 Univariate associations of dietary intake of iron and modifiers of iron absorption with log(serum ferritin; $\mu \mathrm{g} / \mathrm{l})$ for children aged 12-23 months, Auckland, New Zealand (NZ)

\begin{tabular}{|c|c|c|c|c|c|c|c|c|c|c|}
\hline \multirow[b]{3}{*}{ Dietary factor } & \multirow{2}{*}{\multicolumn{2}{|c|}{$\begin{array}{l}\text { All children } \\
\quad(n 170)\end{array}$}} & \multicolumn{8}{|c|}{ Ethnic group } \\
\hline & & & \multicolumn{2}{|c|}{$\begin{array}{l}\text { NZ European } \\
(n 71)\end{array}$} & \multicolumn{2}{|c|}{$\begin{array}{l}\text { Maori } \\
(n 42)\end{array}$} & \multicolumn{2}{|c|}{$\begin{array}{l}\text { Pacific } \\
(n 45)\end{array}$} & \multicolumn{2}{|c|}{$\begin{array}{l}\text { Other } \\
(n 12)\end{array}$} \\
\hline & $r^{2}(\%)^{*}$ & $P$ value & $r^{2}(\%)$ & $P$ value & $r^{2}(\%)$ & $P$ value & $r^{2}(\%)$ & $P$ value & $r^{2}(\%)$ & $P$ value \\
\hline $\log (F e$ intake; mg/d)† & 4 & $0 \cdot 01$ & 8 & 0.03 & 4 & $0 \cdot 24$ & 0 & 0.79 & 0 & 0.92 \\
\hline \multicolumn{11}{|l|}{ Log(Fe intake; mg/d) from } \\
\hline Meat and meat dishes & 1 & $0 \cdot 30$ & 10 & 0.02 & 4 & $0 \cdot 17$ & 0 & 0.72 & 6 & $0 \cdot 44$ \\
\hline Fruit and vegetables & 1 & $0 \cdot 26$ & 1 & 0.59 & 3 & 0.37 & 8 & $0 \cdot 18$ & 2 & $0 \cdot 74$ \\
\hline Cereals & 0 & 0.71 & 0 & 0.90 & 2 & 0.52 & 0 & 0.91 & 3 & 0.57 \\
\hline Milkł & 3 & 0.03 & 9 & 0.01 & 7 & 0.02 & 1 & 0.61 & 3 & $0 \cdot 46$ \\
\hline Breast milk and milk formulas§ & 9 & $<0.001$ & 19 & $<0.001$ & 4 & $0 \cdot 11$ & 3 & $0 \cdot 14$ & 1 & $0 \cdot 76$ \\
\hline Fortified infant foods & 2 & 0.09 & 5 & 0.07 & 0 & 0.91 & 1 & $0 \cdot 70$ & 3 & $0 \cdot 82$ \\
\hline \multicolumn{11}{|c|}{ Other dietary factors and anthropometry } \\
\hline Log(vitamin C intake; mg/d)\| & 9 & $<0.001$ & 15 & $<0.001$ & 3 & $0 \cdot 23$ & 3 & 0.37 & 5 & 0.52 \\
\hline Log(Ca intake; mg/d) & 0 & $0 \cdot 75$ & 1 & 0.55 & 0 & 0.98 & 0 & $0 \cdot 80$ & 21 & $0 \cdot 45$ \\
\hline Log(dietary fibre intake; g/d) & 0 & 0.62 & 0 & 0.88 & 1 & 0.53 & 1 & 0.79 & 7 & $0 \cdot 32$ \\
\hline Birth weight $(\mathrm{kg})$ & 0 & 0.73 & 0 & $0 \cdot 81$ & 1 & 0.62 & 1 & 0.57 & 3 & $0 \cdot 66$ \\
\hline BMI-for-age Z-score & 0 & 0.93 & 0 & 0.96 & 2 & $0 \cdot 40$ & 5 & $0 \cdot 20$ & 0 & $0 \cdot 82$ \\
\hline Weight-for-height Z-score & 0 & 0.84 & 0 & 0.95 & 3 & $0 \cdot 38$ & 5 & 0.19 & 0 & 0.85 \\
\hline
\end{tabular}

*Percentage of variance in value of log(serum ferritin) explained by regression model.

tFor all significant associations, as $\log (\mathrm{Fe}$ intake) increased, log(serum ferritin) increased.

$\ddagger$ As $\log$ (Fe from milk) increased, log(serum ferritin) decreased.

$\S A$ s log(Fe from formulas and breast milk) increased, log(serum ferritin) increased.

$\|$ As $\log (\mathrm{Ca})$ increased, $\log ($ serum ferritin) decreased. 
For children aged 6-11 months (Table 6), serum ferritin increased as birth weight $(P=0.02)$ and as Fe from formulas and breast milk increased $(P=0 \cdot 02)$ and decreased as $\mathrm{Ca}$ intake increased $(P=0 \cdot 01)$. For children aged 12-23 months (Table 7), serum ferritin increased as Fe from formulas and breast milk increased $(P<0.001)$ and as vitamin $\mathrm{C}$ intake increased $(P<0 \cdot 001)$. Serum ferritin decreased as Fe intake from non-human or non-formula milk increased $(P=0 \cdot 03)$.

Associations between dietary factors and serum ferritin varied with ethnicity (Tables 6 and 7). They were present for NZ European and Maori children in both age groups and for Pacific children aged 6-11 months.

For NZ European children aged 6-11 months (Table 6), serum ferritin decreased as Fe intake from cereals increased $(P=0.03)$ and as Ca intake increased $(P=0 \cdot 01)$. In the 12-23 month age group (Table 7 ), serum ferritin increased as $\mathrm{Fe}$ intake from meat and meat dishes $(P=0 \cdot 02)$, milk formulas and breast milk $(P<0 \cdot 001)$ increased and as vitamin $\mathrm{C}$ intake increased $(P<0 \cdot 001)$. Ferritin decreased as Fe intake from milk increased $(P=0 \cdot 01)$.

Among Maori children, for those aged 6-11 months serum ferritin increased as vitamin $C$ intake increased $(P=0 \cdot 03$; Table 6$)$ and for those aged 12-23 months serum ferritin decreased as Fe intake from milk increased $(P=0 \cdot 02$; Table 7$)$. For Pacific children aged 6-11 months (Table 6), serum ferritin increased as Fe intake from breast milk and formula milk $(P=0.003)$ increased and as vitamin $\mathrm{C}$ intake increased $(P<0 \cdot 001)$.

\section{Discussion}

Fe intake was less than the EAR for $25 \%$ of the children in the present study. In the 12-23 month age group, dietary sources of Fe varied with ethnicity. In comparison with NZ European children, Pacific children had a greater daily Fe intake with a larger proportion of their dietary Fe from meat and meat dishes. For Maori children a larger proportion of dietary Fe was from cereals.

Fe intake was associated with body Fe status. Not meeting the EAR increased the risk of ID. Increased Fe intake was associated with increased body Fe stores as measured by serum ferritin concentration. The observed positive (birth weight, breast milk and milk formulas intake, vitamin $\mathrm{C}$ intake) and negative ( $\mathrm{Ca}$ and nonhuman, non-formula milk intake) associations with $\mathrm{Fe}$ status are consistent with the published literature on birth weight, dietary Fe bioavailability and absorption ${ }^{(18)}$.

The relationship between dietary $\mathrm{Fe}$ intake and $\mathrm{Fe}$ stores varied with ethnicity. For NZ Europeans, total Fe intake was associated with Fe stores for children aged 12-23 months but not for those who were younger. In the 6-11 month age group, Fe stores increased as birth weight increased and decreased as Fe intake from cereals increased and as Ca intake increased. In the 12-23 month age group, Fe stores increased as vitamin $\mathrm{C}$ intake increased and as Fe intake from meat and meat dishes, breast milk and milk formulas increased. Fe stores decreased as Fe intake from other milks increased.

For Maori children, Fe intake was associated with Fe stores in both age groups. For Maori children aged 6-11 months, Fe stores increased as vitamin $\mathrm{C}$ intake increased; for those aged 12-23 months, Fe stores decreased as Fe intake from other milk increased. For Pacific children, $\mathrm{Fe}$ intake was associated with $\mathrm{Fe}$ stores for children 6-11 months old but not for those who were older. In this younger age group Fe intake from breast milk and formulas and vitamin $\mathrm{C}$ intake were associated with increased Fe stores. Notably, there were no significant associations of dietary Fe intake with Fe stores for Pacific children aged 12-23 months.

The average daily Fe intake in the present study was comparable to that previously reported for NZ European children. In a random sample of NZ European children who were not breast-fed, the mean daily Fe intake was $8.4 \mathrm{mg}$ (age 6-11 months) and 5.0 mg (age 12-24 months) ${ }^{(21)}$. In a self-selected sample of NZ European infants, daily dietary Fe intakes were $7.8 \mathrm{mg}$ at 9 months and $4.9 \mathrm{mg}$ at 18 months of age ${ }^{(22)}$. The predominant sources of dietary Fe were similar; milk formula and breast milk for those $<12$ months old and cereals for those aged 12 months and older ${ }^{(21)}$.

The median daily Fe intake of children in the present study was low compared with the 2002 US Feeding Infants and Toddlers Study (FITS). In FITS, daily Fe intake was $15 \cdot 2 \mathrm{mg}$ for children 7-11 months old and $9 \cdot 0 \mathrm{mg}$ for children 12-24 months old. These values are $83 \%$ and $43 \%$ greater than for the comparable age groups in our study ${ }^{(23)}$. The energy intakes of the FITS participants were also significantly higher than those in the present study. The methodological differences between these studies do not explain the large differences in Fe intake.

What explains this lower Fe intake in NZ compared with the USA? General dietary habits did not differ in any consistent manner that explains lower $\mathrm{Fe}$ intake. For example, both the proportion of children breast-fed at birth (93\% in present study $v .76 \%$ in FITS) and the median duration of breast-feeding ( $7 v .6$ months) were comparable, as were the proportion ever fed infant formula ( $80 \% v$. 90\%), cow's milk prior to age 12 months $(25 \% v \cdot 41 \%)$ and weaning foods at less than age 4 months (19\% v. 29\%).

Fe supplement use during infancy by children in the present study was less than in FITS $(3 \% \text { v. } 24 \%)^{(7)}$. However, this explains only a proportion of the difference in the adequacy of Fe intake between the children enrolled in these two studies. Of the children in the FITS study who were not receiving Fe supplements, median daily Fe intake was $14.7 \mathrm{mg}$ for 6-11-month-old children and $8.2 \mathrm{mg}$ for $12-24$-month-old children, $77 \%$ and $30 \%$ 
more respectively than that in the same age groups in the present study ${ }^{(7)}$.

Lower Fe content of infant cereals in NZ compared with the USA is one potential explanation. In the USA, infant cereals contain at least $45 \mathrm{mg} \mathrm{Fe} / 100 \mathrm{~g}_{\text {cereal }}{ }^{(24)}$. This level of fortification is effective in preventing ID $^{(25)}$. In NZ, Fe fortification of infant cereals is mandatory only for products used from 6 to 12 months of age and ranges between 20 and $50 \mathrm{mg} \mathrm{Fe} / 100 \mathrm{~g}$ dry cereal ${ }^{(26)}$.

The contribution that dietary factors make to Fe status varied with ethnicity in two ways. First, despite having a larger daily Fe intake and a larger proportion of dietary Fe from meats and meat dishes, Pacific children are at increased risk of $\mathrm{ID}^{(4)}$. Second, there were fewer associations between dietary factors and Fe status for Maori or Pacific children compared with NZ European children. Both of these observations imply that non-dietary factors may be more important determinants of Fe status for Maori and Pacific children.

One of the more important non-dietary factors that affect nutritional status is communicable disease burden $^{(27)}$. For both Maori and Pacific ethnic groups, the frequency and severity of communicable diseases are greater in early childhood $^{(28)}$. These illness episodes are likely to have a negative effect on Fe status by both decreasing dietary intake and altering Fe metabolism as part of the acute-phase response ${ }^{(27,29)}$. Thus policy that seeks to reduce ID prevalence in these ethnic groups needs to consider the cyclical relationship of poor nutrition and increased susceptibility to communicable diseases. ID needs to be considered in the broader context of deficiencies in multiple nutrients and the adverse effect this has on the health of these populations ${ }^{(30)}$.

The sample of children on whom these findings were based was biased. In comparison with the recruited children in whom valid weighed food records were not collected, our sample had fewer children with ID. It is likely therefore that we have underestimated the proportion of children in whom dietary Fe intake was inadequate.

The number of non-Maori, non-Pacific and non-NZ European children enrolled was insufficient to enable many conclusions to be drawn about dietary determinants of their Fe status. As many of these children are new immigrants they will be at risk of consuming diets that do not contain sufficient $\mathrm{Fe}^{(31)}$. The proportions with Fe intakes less than the EAR (24\%) and less than the RDI (80\%) are consistent with this. As population diversity in $\mathrm{NZ}$ is projected to increase, the nutritional adequacy of the diets of these ethnic groups requires greater attention $^{(32)}$.

In the present study dietary Fe intake was derived from two days of weighed diet records for each individual. Although this is not able to provide a true estimate of usual intake, fewer days of dietary record are required to estimate intakes accurately in young children than in other age groups ${ }^{(33)}$. Quantifying associations between dietary $\mathrm{Fe}$ intake and biochemical indices of $\mathrm{Fe}$ status is challenging due to the inability to accurately measure the bioavailability of $\mathrm{Fe}$ from different foods and food combinations eaten as meals. However, we were able to demonstrate the impact of enhancers and inhibitors of dietary Fe absorption on body Fe stores as measured by serum ferritin.

Estimated breast milk volume was determined using DARLING study data derived from test weighing corrected for insensible water losses during feeding ${ }^{(13)}$. These volumes are higher than more recent reported studies in developed countries and could therefore result in a small overestimate of intake ${ }^{(34)}$.

The present study highlights the need for more effective infant nutrition policy in NZ. If the prevalence of ID is to be reduced in this age group then Fe intake needs to be increased. Improving the $\mathrm{Fe}$ density of the diet and acknowledging ethnic differences in food intake that may impact on Fe status should be key policy initiatives.

Assuming no change in current dietary practices, this will require more fortification of the predominant foods consumed by young children. The comparisons made with the USA indicate that greater Fe fortification of infant cereals would appear necessary. Infant Fe supplements need to be given more consistently to premature infants. That increased consumption of non-human, non-formula milks by children aged 12-23 months had a negative effect on body Fe stores requires consideration of the use of formula milks to extend past the currently recommended age of 12 months. The enhancing effect of vitamin $\mathrm{C}$ on $\mathrm{Fe}$ status that was present in ethnic-specific analyses suggests this has the potential to play an important role in policy aimed to improve Fe status.

ID has remained prevalent in NZ since it was first identified as a child public health issue in the $1960 \mathrm{~s}^{(35)}$. If NZ truly desires to build a knowledge economy it must first secure the educational potential of its next generation $^{(36)}$. Reducing the proportion of its children exposed to the adverse cognitive, behavioural and educational consequences of ID is necessary if the nation's intellectual capital is to be realised ${ }^{(37,38)}$.

\section{Acknowledgements}

The project was funded by the Health Research Council of New Zealand (Project Grant \# 99/075). D.R.B. was funded by a research grant from The Starship Foundation, with this grant made possible by financial support from Only Organic Baby Food. The authors have no competing interests to declare. All authors were involved in the design of the study. C.C.G. and C.R.W. supervised the collection of the data. C.R.W. and DRB performed the data analysis and interpretation. C.C.G. completed the first draft of the manuscript which was edited and revised by C.R.W. and D.R.B. 


\section{References}

1. Karr M, Alperstein G, Causer J, Mira M, Lammi A \& Fett MJ (1996) Iron status and anaemia in preschool children in Sydney. Aust N Z J Public Health 20, 618-622.

2. Male C, Persson LA, Freeman V, Guerra A, van't Hof MA \& Haschke F; Euro-Growth Iron Study Group (2001) Prevalence of iron deficiency in 12-mo-old infants from 11 European areas and influence of dietary factors on iron status (Euro-Growth study). Acta Paediatr 90, 492-498.

3. Anon (2002) Iron deficiency - United States, 1999-2000. MMWR Morb Mortal Wkly Rep 51, 897-899.

4. Grant CC, Wall CR, Brunt D, Crengle S \& Scragg R (2007) Population prevalence and risk factors for iron deficiency in Auckland, New Zealand. J Paediatr Child Health 43 , 532-538.

5. Yip R, Walsh KM, Goldfarb MG \& Binkin NJ (1987) Declining prevalence of anemia in childhood in a middleclass setting: a pediatric success story? Pediatrics $\mathbf{8 0}$, 330-334.

6. Yip R, Binkin NJ, Fleshood L \& Trowbridge FL (1987) Declining prevalence of anemia among low-income children in the United States. JAMA 258, 1619-1623.

7. Briefel R, Hanson C, Fox MK, Novak T \& Ziegler P (2006) Feeding Infants and Toddlers Study: do vitamin and mineral supplements contribute to nutrient adequacy or excess among US infants and toddlers? J Am Diet Assoc 106, S52-S65.

8. Gregory J, Collins DL, Davies PS, Hughes JM \& Clarke PC (1995) The Dietary and Nutritional Survey: Children Aged 11/2 to 41/2 Years. Report of the Diet and Nutrition Survey. London: HMSO.

9. Baggett HC, Parkinson AJ, Muth PT, Gold BD \& Gessner BD (2006) Endemic iron deficiency associated with Helicobacter pylori infection among school-aged children in Alaska. Pediatrics 117, e396-e404.

10. Fraser AG, Scragg R, Metcalf P, McCullough S \& Yeates NJ (1996) Prevalence of Helicobacter pylori infection in different ethnic groups in New Zealand children and adults. Aust NZ J Med 26, 646-651.

11. de Onis M, Garza C, Victora CG, Onyango AW, Frongillo EA \& Martines J (2004) The WHO Multicentre Growth Reference Study: planning, study design, and methodology. Food Nutr Bull 25, S15-S26.

12. New Zealand Institute for Crop and Food Research Limited \& Ministry of Health (2008) New Zealand Food Composition Database. http://www.crop.cri.nz/home/products-services/ nutrition/foodcompdata/index.php (accessed November 2008).

13. Dewey KG, Heinig MJ, Nommsen LA \& Lonnerdal B (1991) Adequacy of energy intake among breast-fed infants in the DARLING study: relationships to growth velocity, morbidity, and activity levels. J Pediatr 119, 538-547.

14. Nusser SM, Carriquiry AL, Dodd KW \& Fuller WA (1996) A semiparametric transformation approach to estimating usual daily intake distributions. J Am Stat Assoc 91, 1440-1449.

15. Department of Health and Ageing, Australian Government, Australian National Health and Medical Research Council \& New Zealand Ministry of Health (2006) Nutrient Reference Values for Australia and New Zealand Including Recommended Dietary Intakes. Canberra: Commonwealth of Australia; available at http://www.nhmrc.gov.au/publications/ synopses/n35syn.htm

16. Looker AC, Dallman PR, Carroll MD, Gunter EW \& Johnson CL (1997) Prevalence of iron deficiency in the United States. JAMA 277, 973-976.

17. Anon. (1985) Summary of a report on assessment of the iron nutritional status of the United States population. Expert Scientific Working Group. Am J Clin Nutr 42, 1318-1330.
18. Centers for Disease Control and Prevention (1998) Recommendations to prevent and control iron deficiency in the United States. MMWR Morb Mortal Wkly Rep 47, 1-29.

19. Salmond C \& Crampton P (2002) NZDep2001 Index of Deprivation. Wellington: Wellington School of Medicine and Health Sciences, University of Otago.

20. Auckland Regional Public Health Service (2006) Improving Health and Wellbeing: A Public Health Perspective for Local Authorities in the Auckland Region. Auckland: Auckland Regional Public Health Service.

21. Soh P, Ferguson EL, McKenzie JE, Skeaff S, Parnell W \& Gibson RS (2002) Dietary intakes of 6-24-month-old urban South Island New Zealand children in relation to biochemical iron status. Public Health Nutr 5, 339-346.

22. Heath AL, Tuttle CR, Simons MS, Cleghorn CL \& Parnell WR (2002) Longitudinal study of diet and iron deficiency anaemia in infants during the first two years of life. Asia Pac J Clin Nutr 11, 251-257.

23. Devaney B, Ziegler P, Pac S, Karwe V \& Barr SI (2004) Nutrient intakes of infants and toddlers. J Am Diet Assoc 104, s14-s21.

24. Anon. (1976) Committee on Nutrition: iron supplementation for infants. Pediatrics 58, 765-768.

25. Walter T, Dallman PR, Pizarro F, Velozo L, Peña G, Bartholmey SJ, Hertrampf E, Olivares M, Letelier A \& Arredondo M (1993) Effectiveness of iron-fortified infant cereal in prevention of iron deficiency anemia. Pediatrics 91, 976-982.

26. Food Standards Australia and New Zealand (2008) Australia New Zealand Food Standards Code. Barton: FSANZ; available at http://www.foodstandards.gov.au/thecode/ foodstandardscode.cfm

27. Keusch GT (2003) The history of nutrition: malnutrition, infection and immunity. J Nutr 133, 336S-340S.

28. Ministry of Health (1998) Our Children's Health; Key Findings on the Health of New Zealand Children. Wellington: Ministry of Health.

29. Roy CN \& Andrews NC (2005) Anemia of inflammation: the hepcidin link. Curr Opin Hematol 12, 107-111.

30. Black RE, Allen LH, Bhutta ZA, Caulfield LE, de Onis M, Ezzati M, Mathers C \& Rivera J; Maternal and Child Undernutrition Study Group (2008) Maternal and child undernutrition: global and regional exposures and health consequences. Lancet 371, 243-260.

31. Yeung DL \& Kwan D (2002) Commentary: experiences and challenges in industrialized countries. J Nutr 132, 825S-826S.

32. Statistics New Zealand (2005) National Ethnic Population Projections. Wellington: Statistics New Zealand.

33. Nelson M, Black AE, Morris JA \& Cole TJ (1989) Betweenand within-subject variation in nutrient intake from infancy to old age: estimating the number of days required to rank dietary intakes with desired precision. Am J Clin Nutr 50, $155-167$.

34. Brown K, Dewey K \& Allen L (1998) Complementary Feeding of Young Children in Developing Countries: A Review of Current Scientific Knowledge. Geneva: WHO.

35. Akel R, Frankish J, Powles C, Tyler KR, Watt JM, Weston HJ \& Prior IA (1963) Anaemia in Maori and European infants on admission to hospital. A co-operative survey from six New Zealand Hospitals. N Z Med J 62, 29-33.

36. Anon. (1999) What Is the Knowledge Economy? Wellington: Ministry of Economic Development; available at http:// www.med.govt.nz/templates/MultipageDocumentPage 17263.aspx

37. Pollitt E (1997) Iron deficiency and educational deficiency. Nutr Rev 55, 133-141.

38. Lozoff B, Jimenez E, Hagen J, Mollen E \& Wolf AW (2000) Poorer behavioral and developmental outcome more than 10 years after treatment for iron deficiency in infancy. Pediatrics 105, E51. 